\title{
Philosophiques
}

\section{Liste des livres reçus pour recension}

Volume 45, numéro 1, printemps 2018

URI : https://id.erudit.org/iderudit/1048637ar

DOI : https://doi.org/10.7202/1048637ar

Aller au sommaire du numéro

Éditeur(s)

Société de philosophie du Québec

ISSN

0316-2923 (imprimé)

1492-1391 (numérique)

Découvrir la revue

Citer ce document

(2018). Liste des livres reçus pour recension. Philosophiques, 45(1), 339-340.

https://doi.org/10.7202/1048637ar

Ce document est protégé par la loi sur le droit d'auteur. L'utilisation des services d'Érudit (y compris la reproduction) est assujettie à sa politique d'utilisation que vous pouvez consulter en ligne.

https://apropos.erudit.org/fr/usagers/politique-dutilisation/
Cet article est diffusé et préservé par Érudit.

Érudit est un consortium interuniversitaire sans but lucratif composé de l’Université de Montréal, l'Université Laval et l'Université du Québec à Montréal. Il a pour mission la promotion et la valorisation de la recherche. https://www.erudit.org/fr/ 


\section{Liste des livres reçus pour recension}

Pascal Brissette et Mathieu Lapointe (dir.), Corruption: Montréal et ses démons, Montréal, Leméac, 2016, I 2 pages

Philippe Eon, Philosopher, en un mot. Variations sur le sens du mot spécial, Québec, Presses de l'Université Laval, 20I7, I7 I pages

Michel Fichant et Sophie Roux (dir.), Louis Couturat (1868-1914). Mathématiques, langages, philosophie, Paris, Classiques Garnier, 2017, 363 pages

Sébastien Gandon et Ivahn Smadja (dir.), Philosophie des mathématiques: Logique, preuve et pratiques. Textes clés de philosophie des mathématiques, Paris, Librairie philosophique Vrin, 2017, 383 pages

Joakim Garff, Kierkegaard's Muse: The Mystery of Regine Olsen, Princeton, Princeton University Press, 20I7, 3I3 pages

Katia Genel (dir.), La dialectique de la raison: Sous bénéfice d'inventaire, Paris, Éditions de la Maison des sciences de l'homme, 20I7, 3 I I pages

Jean-Luc Gouin, Hegel. De la Logophonie comme chant du signe, Québec, Presses de l'Université Laval, 2018, 3 I 2 pages

Olivier Huot Beaulieu, La négativité en litige: Heidegger, Hegel et l'origine de la négation dialectique, Rennes, Presses Universitaires de Rennes, 20I7, 3 I9 pages

Kevin Iselin, Le droit pénal à la lumière de l'existentialisme sartrien, Québec, Presses de l'Université Laval, 20I7, I 49 pages

Max Kistler, L'esprit matériel. Réduction et émergence, Paris, Ithaque, 2016, 308 pages

Siegfried Kracauer, Politique au jour le jour, Paris, Éditions de la Maison des sciences de l'homme, 20I7, I83 pages

Mogens Laerke, Christian Leduc et David Rabouin (dir.), Leibniz. Lectures et commentaires, Paris, Librairie Philosophique J. Vrin, 20I7, 383 pages

Maurice Lagueux, Tout en même temps agnostique et croyant, Montréal, Liber, 20I7, 288 pages

Vincent Legeay, L'essence plastique. Aptitudes et accommodements chez Spinoza, Paris, Éditions de la Sorbonne, 2018, I40 pages

Gottfried Wilhelm Leibniz, Discours de métaphysique. Correspondance avec Arnauld, éd. Christian Leduc, Paris, Vrin, 2016, 428 pages

Simon Nadeau, Le philosophe contrebandier. Introduction à l'œuvre de Michel Morin, Québec, Les herbes rouges, 2017, 270 pages

Jean-Marc Narbonne et Josiane Boulad-Ayoub (dir.), Reflets modernes de la démocratie athénienne, Québec, Presses de l'Université Laval, 2017, 228 pages

Julien Rabachou, L'individu reconstitué, Paris, Librairie philosophique Vrin, 20I7, 246 pages

Michel Sasseville, La pratique de la philosophie en communauté de recherche: entre rupture et continuité, avec la collaboration de A. Fournel, C. Mc Carthy et S. Nepton, Québec, Presses de l'Université Laval, 2018, 282 pages.

Georg Simmel, L'argent dans la culture moderne et autres essais sur l' "économie de la vie», trad. et prés. par A. Deneault, $2^{\mathrm{e}}$ édition, Québec, Presses de l'Université Laval, 2018, I95 pages 
Scott Soames, The Analytic Tradition In Philosophy, vol. 2, Princeton, Princeton University Press, 2017, 423 pages

Pierre Steiner, Qu'est-ce que la pensée?, Paris, Librairie philosophique Vrin 2017, I 27 pages 